\title{
Global Warming and Climate Change: A Critique on International Law and Policy
}

\author{
* Dr. Lisa P Lukose 1 \\ 1 University School of Law and Legal Studies, Guru Gobind Singh Indraprastha University, New Delhi, India \\ E mail: drlisarobin@ipu.ac.in
}

\begin{tabular}{l}
\hline A R T I C L E I N F O: \\
\hline Article history: \\
Received 2 August 2017 \\
Accepted 28 August 2017 \\
Available online 12 October \\
2017 \\
\hline Keywords: \\
Solar collector; \\
Thermal storage; \\
Latent heat storage. \\
\begin{tabular}{l} 
This work is licensed under a \\
Creative Commons Attribution \\
NonCommercial - NoDerivs 4.0. \\
"CC-BY-NC-ND" \\
\hline
\end{tabular} \\
\hline
\end{tabular}

\begin{abstract}
A B S T R A C T
Global warming and climate change, a multidisciplinary topic is a matter of international concern. There are some international environmental treaties related to global warming and climate change. The most significant international agreement in this area is - UNFCCC - the United Nations Framework Convention on Climate Change adopted at the Rio Earth Summit in 1992 and ratified by 195 countries. It mainly deals with greenhouse gases emissions mitigation, adaptation and finance starting in the year 2020. The Kyoto Protocol which extends the 1992 UNFCC mandates State Parties to reduce greenhouse gas emissions: its two basic premises are - global warming exists, and human-made CO2 emissions caused global warming. The Kyoto Protocol came into force in 2005 and each COP has served as the 'meeting of parties' to Kyoto Protocol such as COP13 (Bali, 2007), COP15 (Copenhagen, 2009), COP16 (Cancun, 2010), COP17 (Durban, 2011), COP18 (Doha, 2012), COP19 (Warsaw, 2013), COP21 and (Paris, 2015).There are other international legal instruments such as 1979 Geneva Convention on Long-Range Trans-boundary Air Pollution. Against this backdrop, this paper will critically examine the existing international legal regime (treaties, conventions, agreements, etc.) on global warming and climate change.
\end{abstract}

JOURNAL OF CONTEMPORARY URBAN AFFAIRS (2017) 1(3), 38-42.

https://doi.org/10.25034/ijcua.2018.3677

www.ijcua.com

Copyright (C) 2017 Journal Of Contemporary Urban Affairs. All rights reserved.

\section{Introduction}

Global warming and climate change is no longer a problem of the future generation, though it continues to affect future generations. Global warming from carbon dioxide (C02) and other greenhouse gases pose a severe threat to the international community. The Earth's atmosphere is dilapidated at an unprecedented rate. Law plays a critical and important role for the effective and equitable climate change governance. There is some legal framework adopted to address the issues relating to global warming and climate change. However, global warming and climate change is not an isolated topic to address independently. It is connected to all environmental issues. This paper attempts to examine:

1. Why is global warming of serious concern?

2. How does the present international legal regime respond to climate change?

3. What are the lacunae in the existing international laws?

*Corresponding Author:

University School of Law and Legal Studies, Guru Gobind Singh Indraprastha University, New Delhi, India

E-mail address: drlisarobin@ipu.ac.in 
4. How can climate law respond better to the diverse contemporary requirements?

\section{Method and Material}

The author has adopted a doctrinal and analytical method to develop this paper. The material is drawn from both primary and secondary sources. The primary sources are the legal instruments while secondary sources are offline and online resource materials which are cited in this paper at relevant places.

\section{Effect of Global Warming}

The immediate effect of global warming is climate change. The impact of global warming is in fact much beyond climate change. It adversely affects human development, and it does have a long-term impact on the environment. Temperature increase, extreme weather events, flood, drought, sea level rise, erratic precipitation, melting glaciers, reduced snow cover are few impacts to mention. Its impact on aquaculture, biological diversity, agriculture, health, and livelihood is dangerous. It also adversely affects a broad range of other human rights (Workshop in the Context of the UNFCCC COP 20,2014 ), for example, right to food, indigenous peoples right, etc.

A large section of the world population is suffering from the effects of climate change. In 2009 it was estimated that about 300000 people die annually due to the adverse effect of climate change and 325 million are further seriously affected (Annan, 2009). Since developing countries have less financial and technological resources, they are more vulnerable to the impacts of climate change.

\section{UNFCCC 1992}

The United Nations Framework Convention on Climate Change (one among the three adopted at the Rio Earth Summit-1992)' is described as "first steps to a safer future" which was a global response to climate change. Because the global community for the first time recognized and accepted that the climate change is a 'problem' despite having less scientific evidence than now. It is adopted on 9 May 1992 and came into force on 21 March 1994. It is one of the most widely accepted treaties having a near-universal membership. It

\footnotetext{
${ }^{1}$ The other two sister Rio Earth Summit Conventions are (i) the UN Convention on Biological Diversity and (ii) the Convention to
}

neither has any binding limit on the emission of green gas for member countries nor has enforcement mechanisms.

The basic aim of UNFCCC is to prevent dangerous human interference with the climate system. By borrowing from the Montreal Protocol 1987, it bounds member states to "act in the interests of human safety even in the face of scientific uncertainty." UNFCCC is an international framework seeking global cooperation to combat climate change by limiting average global temperature increases and the resulting climate change and coping with impacts that were, by then, inevitable. It obliges the members to stabilize greenhouse gas concentrations at a level that would prevent dangerous anthropogenic interference with the climate system. It states how specific international treaties/protocols/Agreements may be negotiated to accomplish UNFCCC objectives.

\section{UNFCC to KYOTO}

By the agreements adopted in Copenhagen (2009) and Cancun (2010) countries promised to set a goal of maintaining temperature increases below 2 degrees Celsius above pre-industrial levels. It also explored financial options for implementation of REDD-plus actions. The developed countries committed to mobilizing $\$ 100$ billion a year in public and private finance for developing countries by 2020. COP 17 at Durban (2011) recognized that "smart government policy, smart business investment, and the demands of an informed citizenry, all motivated by an understanding of mutual selfinterest, must go hand in hand in pursuit of the common goal."

COP 18 Doha (2012) resulted in an amendment to the Kyoto Protocol establishing a second commitment period from 2013-20. It also added more item to list of greenhouse gases. At COP 19 in Warsaw (2013) the governments were encouraged to submit their intended nationally determined contributions (INDCs) to the Paris Agreement. INDCs represent member country's self-defined mitigation goals from 2020. 190 countries accounting for 99 percent of global emissions have already submitted INDCs to the UNFCCC. At COP 20 in Lima (2014) more than

Combat Desertification. All the three conventions aim to encourage mutual cooperation for developing synergies in their activities. Now it incorporates Ramsar Convention on Wetlands as well. 
190 countries pledged to develop new" urgency towards fast-tracking adaptation and building resilience across the developing world" (Lima Call for Action).

\section{The Kyoto Protocol}

The Kyoto Protocol which was developed under the UNFCCC's charter was adopted in 1997 subsequent to the negotiations from 1995 launched to strengthen the global response to climate change. It is a legally binding international instrument with 192 countries' ratification. The main aim of the protocol is to provide specific emissions reduction targets to industrialized nations whose activities mainly cause global warming. It is known as global climate treaty as it extends UNFCCC by requiring countries to reduce greenhouse gas emissions; based on the fact that global warming exists and human-made CO2 emissions have caused global warming. It is a binding instrument requiring developed nations (35 industrial nations) to reduce the emission of six major greenhouse gases to 5.2 percent below from their 1990 levels since they are historically responsible for the present levels of greenhouse gases in the atmosphere. The first commitment period was from 2008 to 2012 and the second from 2013 to 2020 (Doha Amendment to the Kyoto protocol; 37 countries have binding targets). Countries failing to meet the protocol standards are required to pay a carbon tax. It thus helps the state parties to mitigate global warming.

\section{Criticism}

The nations are divided over the benefits of the Koyoto protocol. Some countries have refused to ratify the protocol as they increasingly burn fossil fuels for energy. Sudan, Afghanistan and United States are the examples for countries which refused to ratify though the US itself emits $35 \%$ of the total greenhouse gases in the universe. When most polluter countries are not participating, the protocol remains an idea. Japan, New Zealand, Canada, and Russia though have participated in first-round, they have not taken have not taken commitments in the second period. Countries like China, Brazil, and India may surpass the United States emissions within 25 to 30 years. Critics opine that in order for the atmosphere to catch up with the greenhouse gases there must be 60 percent reduction of greenhouse gases whereas the treaty demands an average of 5.2 percent reductions. It is also apprehended that the targets set forth by the treaty cannot be reached by members as $\mathrm{CO} 2$ emissions are increasing. When the protocol mandates reduction of emission most of the countries is ill-equipped to meet the situation with less access to alternative forms of energy. Further, it is silent about 'climate change-related threats to state sovereignty (Badrinarayana, 2010).

\subsection{PARIS CLIMATE ACCORD}

The 2015 Paris Agreement/Climate Accord, which is a separate instrument under the UNFCCC was adopted at the 21 st session of the Conference of the Parties to UNFCCC (COP 21) on 12 December 2015 in Paris and came into force on November 4, 2016. 195 countries have adopted this agreement. This is the latest step in the UN climate change regime which charts a new course in the global effort to fight climate change measures to be taken after 2020 when the second Kyoto commitment period ends. The Paris Agreement seeks to accelerate and intensify the actions required for a sustainable low carbon future. Its main purpose is to strengthen global action plan to climate change by maintaining/limiting a global temperature rise below 2 degrees Celsius. It further aims to limit the increase to $1.5^{\circ} \mathrm{C}$.

The Agreement also aims to strengthen the ability of countries to deal with the impacts of climate change. The three main components of the Paris Accord are: (i) the Paris Agreement setting common goals, commitments and expectations, (2) the intended "nationally determined contributions" (NDCs) submitted by more than 180 countries and (3) the thousands of contributions offered by companies, states, cities and civil society organizations. The agreement envisages that successive NDC of each party will "represent a progression" than its previous NDC and also "reflect its highest possible ambition."

NDC are however not legally binding obligations. It provides for more transparency and governmental accountability by "reporting to each other and the public on how well they are doing to implement their targets." Other important aspects of the agreement are:

- Parties are committed t to "prepare, communicate and maintain" successive NDCs

- Parties have to "pursue domestic mitigation measures" to achieve NDCs;

- They have to report on emissions and progress in implementing NDCs regularly. 
It has two long-term mitigation goals: (i) a peaking of emissions as soon as possible (Since it will take longer for developing countries, and (ii) net greenhouse gas neutrality in the latter half of the century. Countries are in the process of negotiating the detailed rules to be adopted in 2018 to implement the Paris Agreement.

\section{Suggestions and Recommendations}

Countries have to promote energy efficiency and renewable energy actively. Countries like India, Mexico, South Africa, Saudi Arabia, Brazil, etc. have cut fossil fuel subsidies significantly. The countries have to encourage people to use and convert their energy usage to cleaner energy such as wind power, solar power, hydropower, geothermal power, biomass, etc.

Law and governance improvements must be taken seriously at both national and international levels for climate change mitigation and adaptation. Governments must urge for compensated reduction and compensated conservation wherein carbon can be saved by reducing deforestation and degradation and also carbon is added through conservation, sustainable management of forests and increase in forest cover - afforestation and reforestation (Subramaium, 2016).

Polluting states must have legal and ethical (Mayer, 2013), obligation to compensate - both prospective and retrospective responsibility. This will also help to address the human right issues in climate change regime (Bouthillier, 2012).

There must be more and more diverse interactions between public and private actors. The climate laws negations must ensure more effective participation of members. It is being criticised that out of more than 190 countries only about twenty countries control climate change negations. ${ }^{2}$

The existing climate law does not cover related environmental issues such as the impact of intellectual property rights (IPR) on the environment - for instance, the impact of genetically modified organisms on the environment. The climate law's reach must be extended to cover topics like IPR. (Rimmer, 2011). Global warming and climate change are two sides of the same coin. However, this is not an isolated issue. It is interlinked with all environmental issues. Hence, it is a part of sustainable development. To reduce the adverse effect of climate change, the countries have to commit themselves to stop deforestation: REDD and REDD Plus envisages that developing countries have to reduce "emissions from deforestation and forest degradation." They have to consider policy approaches for the "conservation, sustainable management of forests, and enhancement of forest carbon stocks in developing countries."

\section{Conclusion}

150 years of industrialization have rendered the future of the Mother Nature at stake which will drastically change the equation of coming generations. It is predicted that the average temperature of the atmosphere will raise minimum by 10 degrees in the next century. Kyoto protocol has encouraged innovators and inventors to streamline their R\&D for technologies that reduce greenhouse gas emissions. Countries have to accelerate research in alternate forms of energy. There must be international cooperation taking into consideration the legitimate requirement of developing and least developing countries to develop without compromising their responsibility for sustainable development. Then only the ultimate objective of UNFCCC- to achieve a level "within a timeframe sufficient to allow ecosystems to adapt naturally to climate change, to ensure that food production is not threatened and to enable economic development to proceed in a sustainable manner" can be achieved. The other two sisters Rio Earth Summit Conventions are (i) the UN Convention on Biological Diversity and (ii) the Convention to Combat Desertification. All the three conventions aim to encourage mutual cooperation for developing synergies in their activities. Now it incorporates Ramsar Convention on Wetlands as well.

\section{References}

Annan, K. (2009). Anatomy of silent Crisis. Global Humanitarian Forum.

Badrinarayana, D. (2010). Global Warming: A Second Coming for International Law"? .Washington Law Review, 85, 254-292.

Bouthillier, Y (Ed.). (2012). Poverty Alleviation and Environmental Law. IUCN Academy of Environmental Law series.

Rimmer, M.. (2011). Intellectual Property and Climate Change: Inventing Clean Technologies. UK: Edward Elgar Publishing Ltd.

\footnotetext{
2 Daniel Bodansky, The Copenhagen Climate Change Conference: A Post-Mortem
} 
Subramaium, G. (2016). Climate Change and Reduction of Emission Issues Relating to Deforestation and Environmental degradation in India. India: Indian Law Institute.

Mayer, B. (2013). Climate Change and International Law in the Grim Days. EJIL, 24, 947-970.
Workshop in the Context of the UNFCCC COP 20. (2014). LAW, GOVERNANCE AND CLIMATE CHANGE An International Law and Policy. Lima, Peru. Centre for International Governance Innovation and the Centre for International Sustainable Development Law. 